\title{
Biomedical Informatics in the Desert - A New and Unique Program at Arizona State University
}

\author{
R. A. Greenes, S. Panchanathan, V. Patel, H. Silverman, E. H. Shortliffe \\ Department of Biomedical Informatics, Arizona State University and \\ University of Arizona College of Medicine, Phoenix, in partnership with Arizona State University
}

\begin{abstract}
Summary
Objectives: A new academic Biomedical Informatics (BMI) Program in Phoenix, Arizona, embodies a unique organizational structure to draw on the strengths of a computer science and informatics school and the biomedical and dinical strengths of a college of medicine, in an effort to infuse informatics approaches broadly.

Methods: The program reflects a partnership of fwo state universities that situates the Arizona State University (ASU) Department of BMI on a new downtown Phoenix Biomedical Campus with the University of Arizona (UA) College of Medicine in partnership with ASU (COMPHX). Plans call for development offaculty and expertise in the four major subdomains of BMI, as well as in various cross-cutting capabilities.

Results: Coming into existence in a state that is investing significantly in biomedical science and technology, BMI has already developed Masters and PhD degree programs, is working with COMPHX to integrate informatics intensively into the education of the medical students, and has been authorized to plan for an undergraduate program in BMI. Reflecting the statewide emphosis on the biomedical and health sector, the growing faculty are engaged in a number of research partnerships and collaborative centers.

Conclusions: As one of the newest academic BMI programs istaking shape in Arizona, it is embarking on a wide-ranging educational program and a broad research agenda that are now in their earliest stages.
\end{abstract}

\section{Keywords}

Biomedical informatics, education, academic departments, training

Geissbuhler A, Kulikowski C, editors. IMIA Yearbook of Medical Informatic 2008. Methods Inf Med 2008; 47 Suppl 1:150-6

\section{Introduction}

The Arizona State University (ASU) Department of Biomedical Informatics (BMI) is one of the newest departments of BMI in the world - as of this writing being less than one year old. It also has the distinction of being unique in its conception, the organizational framework in which it is embedded, its constituency, and hence its mission. Arizona is one of the youngest states in the United States, and one of the most rapidly growing. Phoenix, the capital of Arizona, has recently overtaken Philadelphia as the fifth largest city in the US. Although Arizona has thrived in recent years on tourism and real estate development, reliance on these twin engines as primary contributors to growth has made the state's economy vulnerable to potential downturns. Recognizing this, the State of Arizona has made considerable investment over the past five years in the state's infrastructure, its university system, and in public-private partnerships aimed at building a strong research base and stimulating science and technology industry, with an emphasis on the biosciences. Because these activities are still in their early stages, there is a pervasive focus on cooperation and large-scale initiatives in order to make significant advances quickly, as a result of which the barriers to collaboration among entities that traditionally compete with one another in other locales are currently much less difficult to overcome in Arizona. The re- cent dramatic growth and change in the nature of ASU is one of the most visible manifestations of this situation. Although ASU has long been one of the largest universities in the United States, it has in the last 5-6 years embarked on a path to become a leader in education and research, alongside its more well-known sister institution, the University of Arizona (UA). Led by President Michael Crow since 2002, ASU has espoused goals for the "New American University" [1] including intellectual fusion, social embedment, use-inspired scholarship, entrepreneurship, and knowledge without boundaries. The university has made major strides in achieving these goals through substantial increases in budget from all sources over this time period, and emphasis on development of centers of excellence in innovation and research.

Phoenix, despite its size and growth, is the only city in the US of comparable population that had been without a medical school. UA, based in Tucson, Arizona (100 miles to the south), has been the home of the state's sole allopathic college of medicine, founded 40 years ago. With the growth of Phoenix, the state legislature has discussed the possibility of a second biomedical campus for almost 30 years, with debates about whether a new school in Phoenix should be an expansion of the existing UA school in Tucson or a new school of Arizona State University. The debate was resolved in 2004 when the presidents of the two universities, in discussions with 
the Arizona Board of Regents who oversee both ASU and UA, agreed to create a new campus of the UA College of Medicine in Phoenix, but to embark on this effort through a partnership with ASU. In particular, as a visionary initial contribution to the new biomedical campus, which was to be located in downtown Phoenix on city-owned land, ASU undertook the creation of a Department of Biomedical Informatics. The department was established in the School of Computing and Informatics, in the Ira A. Fulton School of Engineering, but placed physically on the new biomedicine campus, rather than with the rest of the engineering school (in Tempe, immediately adjacent to Phoenix). The new expanded college was named the "University of Arizona College of Medicine - Phoenix, in partnership with Arizona State University", hereafter referred to simply as COM-PHX. It emerged as part of an ambitious plan for a 28-acre Phoenix Biomedical Campus (PBC) that would house not only the COM-PHX and ASU's BMI, but also the private Translational Genomics Research Institute (TGen, further described below), the Phoenix programs of the University of Arizona College of Pharmacy, ASU's College of Nursing and Health Innovation, plus others as new buildings are built, and the Allied Health Professions programs of Northern Arizona University.

As an additional contribution to the new biomedical campus, ASU is providing cross-appointed faculty members for the medical school's basic science faculty, which began its courses for first year medical students when the first 24 students were enrolled in August, 2007. This cooperation between ASU and UA is the first of its kind between these two traditionally competitive universities, and is embodied in a new building named the Arizona Biomedical Collaborative-1 (see Fig. 1). ABC-1 has four floors with a total of 88,000 sq. $\mathrm{ft}$., the lower two floors of which house the
ASU Department of BMI and the upper two floors the UA Department of Basic Medical Sciences. With half of this space, approximately 44,000 sq. ft., devoted to BMI, the new building is well equipped with high speed networking and connection to ASU's High Performance Computing resources, its own server room, and advanced teleconferencing capabilities. Classrooms are in other facilities of COM-PHX. ABC-1 has a flexible layout that is thus entirely devoted to faculty offices, graduate student workspaces, conference areas, and space for laboratories and research clusters.

In as much as departments of BMI have largely grown up in medical schools or hospital-based clinical departments, the ASU Department of BMI's organizational positioning within the newly created inderdisciplinary School of Computing and Informatics (SCI) is somewhat unique. SCI also includes a strong Department of Computer Science and Engineering and an emerging program in interdisciplinary Informatics. BMI's home in SCI and its close association with the Department of Computer Science and Engineering enable it to tap easily into and to engage faculty of the School of Engineering in BMI research, yet its location on the Phoenix Biomedical Campus fosters daily interaction with biomedical science and health care colleagues (see Fig. 2). The Chair of the BMI department reports to the Director of SCI who in turn reports to the Dean of the Ira A. Fulton School of Engineering. The Dean reports to the Provost of the University. It is important to note that BMI is a priority of ASU President Michael Crow, who personally advocated for significant special investment that has been provided by the State of Arizona, and has also invested in it from his special initiatives fund.

As mentioned, the $\mathrm{PBC}$ also is home to the Translational Genomics Research Institute. (TGen), a non-profit organi-

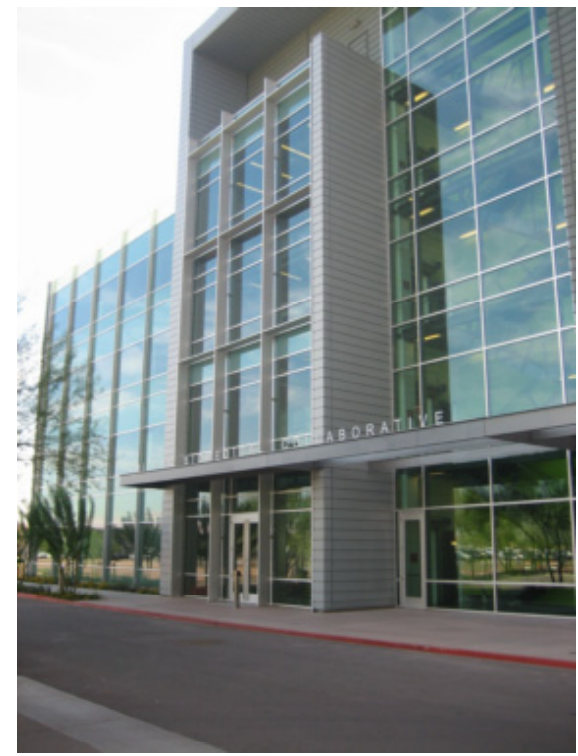

Fig. 1 The new Arizona Biomedical Collaborative-l building on the Phoenix Biomedical Campus, housing the Arizona State University Department of Biomedical Informatics on the first two floors. The upper two floors are occupied by the Department of Biomedical Sciences of the University of Arizona College of Medicine-Phoenix in Partnership with Arizona State University (COM-PHX).

zation established in 2002 with state and private foundation funding. TGen has become a major player in development and testing of clinical applications of genomics and is a key element in the state's bioscience development strategy. Planning is underway for major development of the PBC over the next 10 years including a university-affiliated hospital and medical center. In addition, relationships of both UA and ASU with surrounding health care organizations are already quite strong, owing to clinical clerkships that UA has had with Phoenix hospitals for many years (resulting in UA teaching faculty appointments for many local physicians) and research collaborations of ASU with these institutions. The Department of BMI itself has collaborative projects with Mayo Clinic, Banner Health/Good Samaritan Hospital, Maricopa Integrated Health System, Barrow Neurological Institute/St. Joseph's Hospital, the Phoenix Veterans Administration Hospital, and several 


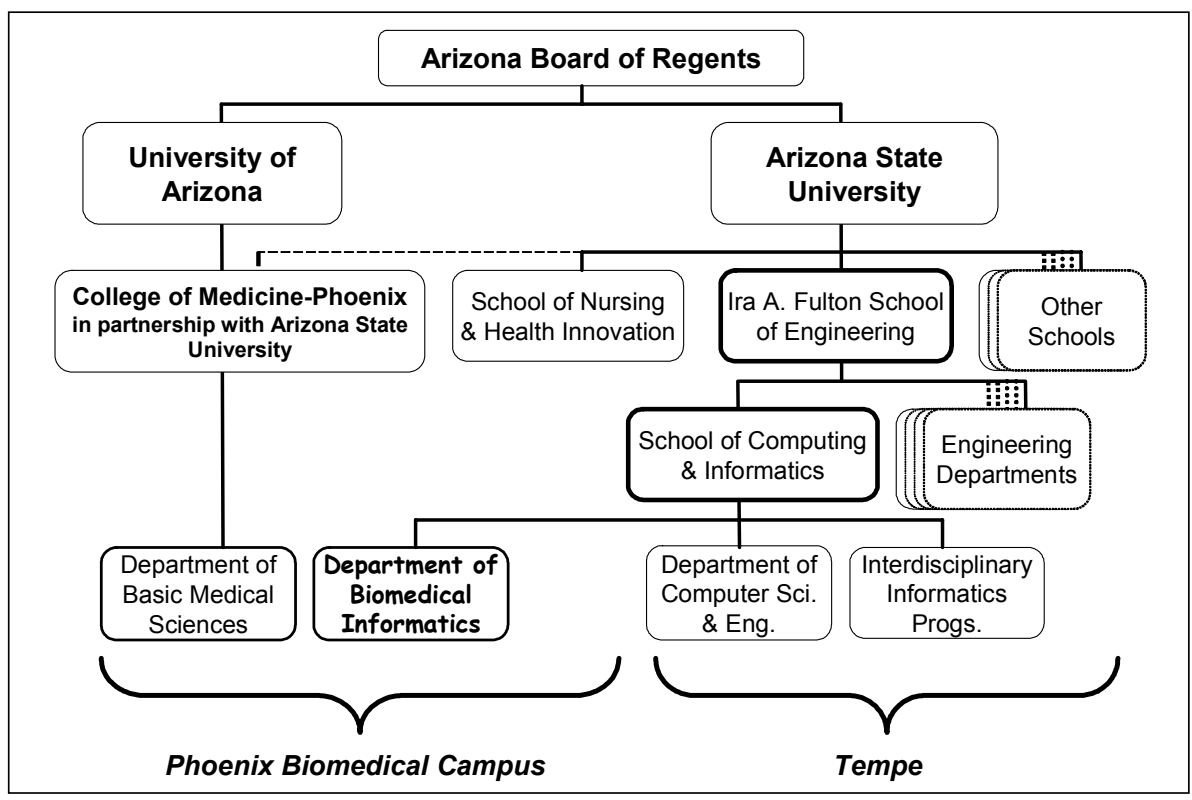

Fig. 2 Organizational framework for the Arizona State University Department of Biomedical Informatics as a Department in the Ira A. Fulton School of Engineering, in its School of Computing and Informatics, but physical location in the Phoenix Biomedical Campus where it is closely associated with the COM-PHX. Only two of the 4 campuses of ASU and only the Phoenix location of UA are depicted, and only selected schools, colleges, and departments are shown that are pertinent to the organizational positioning of BMI.

other clinical institutions. This is consistent with the goal of the state planners who, in establishing the PBC, envisioned that biomedical science and health care development on the campus would stimulate research and development broadly and serve as an engine for economic transformation and growth in Phoenix and in the State of Arizona. Although the collection of activities is evolving as faculty are being brought on and new relationships established, the initial research foci and centers of BMI are described in Section 3.

The Department of BMI came into existence based on early recognition of its centrality to biomedical research and health care and the key role it could play in the scientific/ technical and economic transformation process in Arizona. BMI is explicitly identified in both state and municipal legislative initiatives and funding programs, and has enjoyed a high level of support from both universities and from the commu- nity. This and the resources committed to its development have been key factors in attracting the initial leadership and faculty of this new Department.

\section{History}

The recognition of need for BMI actually dates back a number of years. Reports by the Arizona Department of Commerce and the Battelle Technology Partnership Practice in the early part of this century cited the need for increased capacity in the area of BMI in Arizona [2]. The Arizona Board of Regents, in its August 4, 2004, Memorandum of Understanding Regarding the Expansion of Medical Education and Research in Phoenix, charged ASU with the planning, design, and development of a new Department of BMI [3]. A focus on BMI had also been proposed and was supported by ASU's visionary President Michael Crow who, in a pre- vious leadership position at Columbia University, became familiar with that school's strong Department of BMI and was committed to building a world-class BMI program at ASU.

In response to this charge, a small group of representatives from key departments at ASU and two of its partner institutions, the Mayo Clinic and the Barrow Neurological Institute, met in late 2004 to discuss initial planning for the Department of BMI. The taskforce was co-chaired by Drs. Sethuraman Panchanathan, Director of the School of Computing and Informatics, and George Poste, Director of the Biodesign Institute at ASU. A taskforce report was issued on December 10, 2004. The report presented a vision for a Department of BMI at ASU and a justification for its development. The report also contained a thorough assessment of the strengths of ASU and its partner institutions in the area of BMI; a comprehensive listing of research grants, investigators, and courses currently available at ASU related to BMI; and potential initial research foci for the program based on ASU's research strengths.

The taskforce used the term "biomedical informatics" to describe the union of computing and informatics with basic biological and medical research, clinical practice, imaging, and public health [4]. The subdisciplines of BMI focusing on bioinformatics, imaging informatics, clinical informatics, and public health informatics are more fully defined in the taskforce report.

Based on the task force recommendations, and despite the absence at ASU of significant research or education in BMI, the School of Computing and Informatics at ASU decided to aim for a world-class Department of BMI, building on a partnership between academic researchers, clinical practitioners, and regional health care providers. The programs and degrees administered through the Department 
would prepare individuals to make major contributions to the creation and evaluation of computational and informatics tools for biomedical and clinical research, health care practice and administration, public health, and education of health professionals and patients.

This vision statement was developed in accordance with the guiding principles set forth by the American College of Medical Informatics, the National Institutes of Health, and the Association of American Medical Colleges [4-6]. Moreover, the goals for the Department were developed with the design imperatives set forth by ASU's President Crow for transforming ASU into a leading public metropolitan research university, as cited above [1].

An advisory board was assembled in Fall, 2005, to help guide the evolution of the department, which included key national leaders in BMI - Edward Shortliffe (at Columbia University at that time and subsequently the founding Dean of the COMPHX); Robert Beck, Fox Chase Cancer Center (Advisory Board Chair); Mark Musen, Stanford; Joyce Mitchell, Utah; Christopher Chute, Mayo; Suzanne Bakken, Columbia; Gustavo Stolovitsky, IBM; George Poste, ASU Biodesign Institute; and Michael Bittner, TGen. The first advisory board meeting and a oneday symposium (http://sci.asu.edu/news/ bmi_symposium/) were held in January, 2006, to raise the awareness of BMI in the Phoenix metropolitan area as well as to plan for the building of the department.

The Department of BMI was officially established in 2007, at which point Vimla L. Patel, PhD, DSc, formerly from Columbia University, became Interim Chair of the department. She was joined by William Johnson, $\mathrm{PhD}$, a long-time faculty member at ASU and Director, Center for Health Information and Research, and by Edward H. Shortliffe, $\mathrm{MD}, \mathrm{PhD}$, newly appointed Dean of the COM-PHX, and Howard Silverman,
MD, MS, also at COM-PHX and involved in curriculum design for BMI and Com-PHX. Several new faculty were recruited, including: Trevor Cohen, MD, $\mathrm{PhD}$, from Columbia, Valentin Dinu, $\mathrm{PhD}$, from Yale, Douglas Fridsma, MD, $\mathrm{PhD}$, from University of Pittsburgh, Kanav Kahol, PhD, from ASU, and Graciela Gonzalez, PhD (research faculty) from ASU. Robert A. Greenes, MD, $\mathrm{PhD}$, formerly of Harvard and Brigham and Women's Hospital, became the new Ira A. Fulton Chair and Professor of BMI in September, 2007, and Vimla Patel moved to her current role as Professor and Vice Chair of BMI, with a focus on education and training programs.

An M.S. program in BMI was approved and began in Fall 2007, with a class of 13 students. A PhD program has been approved by the Arizona Board of Regents, to begin in Fall, 2008. We have also received authorization to plan an undergraduate program to begin Fall, 2009, which will focus on training a highly selective group of students for the workforce or for entry into graduate programs. In addition, the Department of BMI participated in teaching the first class of 24 first year medical students at COM-PHX in 2007. Biomedical informatics is an explicit emphasis and distinguishing characteristic of the curriculum of the COM-PHX, and medical students will be receiving instructions and experience with informatics concepts throughout all four years of their training, as elaborated in Section 4.

\section{Goals and Foci}

The goals of the Department of Biomedical Informatics are:

1. To focus on use-inspired research that will result in demonstrable improvements in patient care and biomedical research.

2. To become a nationally recognized leader in biomedical informatics research and development.
3. To embrace broad collaborations with local and regional partners.

4. To leverage research expertise in Arizona.

5. To provide an educational experience that is truly interdisciplinary, by bridging traditional boundaries in scientific and medical education.

6. To train a new generation of physicians and other health care professionals facile in biomedical computing.

7. To serve as a resource to Arizona's biomedical/bioscience community and public health agencies.

8. To contribute to the economic development and well-being of the community by supporting and advancing bioscience and biomedical research in Arizona.

The ASU Department of BMI is in a growth phase, in terms of degree programs, student body, faculty, and staff. As detailed in Section 4, the educational mission includes not only graduate M.S. and Ph.D. programs but instruction of medical students at the COM-PHX, and planning for an undergraduate program to begin in 2009. Current and projected budgets call for growth of tenure-line faculty to more than 20 full-time equivalents (FTEs) by 2011 , with the actual numbers of individuals, based on joint and secondary appointments, expected to be over 30. Together with affiliated and adjunct faculty, total faculty size is expected to be $50-60$ by 2011 .

The early relationships with academic, clinical, community and other partners now being developed will set the tone and focus for the Department for the next several years. The Department has begun its life engaged in a variety of highly collaborative and potentially large-scale projects, in addition to several investigator-led initiatives. The large scale projects have come about because of the broad initiatives being carried out in Arizona and by the expansion of its state universities. These initiatives 
in 2007, for example, include: (1) a statewide initiative to put together a comprehensive approach to support clinical and translational research; (2) the formation of a new Partnership for Personalized Medicine, with $\$ 45 \mathrm{M}$ in initial funding, focused on proteomics and high throughput diagnostics; (3) a Medicare transformation grant to the state Medicaid agency, the Arizona Health Care Cost Containment System (AHCCCS, pronounced "access") to develop an electronic medical record (EMR) interface to its Medicaid providers, for data aggregation and clinical decision support; and (4) work by the Arizona Health eConnection, a consortium of public and private health care organizations, payers, and agencies, including AHCCCS, to expand this goal and to develop a statewide Health Information Exchange.

The Department of BMI is seeking to develop areas of focus in each of the primary subdomains of BMI - bioinformatics, imaging informatics, clinical informatics, and public health informatics. But in addition, capitalizing on its relationship with engineering, computer science and informatics faculty, it is seeking to expand on a number of cross-cutting informatics themes such as such as cognitive science, predictive modeling, multimedia and visualization, simulation, and embedded systems. It also seeks to develop and adopt formal approaches to knowledge representation, communication, and workflow that facilitate research collaboration and accelerate the translational steps between discovery, application, validation, and dissemination of advances. The Department of BMI has two centers, with others in planning stages. The existing centers are a Center for Decision Making and Cognition (http://cognitive.asu.edu), directed by Vimla L. Patel, PhD, DSc, and the Center for Health Information and Research (http://chir.asu.edu/), directed by William Johnson, PhD. Dr. Patel's re- search program includes collaborative studies of decision making and patient safety in critical care settings, working with hospitals in other states (as well as Banner Good Samaritan Hospital in Phoenix) and with researchers from the University of Texas in Houston. Dr. Johnson's group has established a large statewide database with claims data and expanding categories of clinical data, known as Arizona HealthQuery, that is a powerful resource for health services research and health policy decision support. Since COM-PHX on the Phoenix Biomedical Campus will not have a university-affiliated hospital or other clinical facilities for several years, a major direction of growth of the Department's activities can be expected to leverage collaborations, such as those that have already begun, with research and clinical partner institutions, government agencies, payers, and industry.

\section{Educational Programs in BMI at ASU}

ASU is undertaking a wide range of educational initiatives from the outset. M.S. program. The graduate program in Biomedical Informatics is designed to meet the rapidly growing need for professionals in the field with preparation that integrates expertise in informatics, computer science, cognitive and decision sciences, statistics, and biomedical sciences with knowledge of the clinical environment, and the procedures, organization, and workflow processes of the health care system.

The Master of Science (M.S.) degree program is a research-oriented program with a thesis requirement, designed to give students strong preparation for academic, industry, or health care system informatics careers. The initial thirteen students have diverse backgrounds in engineering, computer science, medicine, nursing and psychology. The program features a sequence of courses specifically designed to bring together clinicians, biological scientists, and informatics researchers in teams, applying new developments in informatics theory to clinical and biological practice. This new program is supported by a number of collaborators including faculty and researchers from the COM- PHX, Mayo Clinic, Barrow Neurological Institute, Banner Health System, Maricopa Integrated Healthcare System, TGen, and AHCCCS. This collaborative approach makes the M.S. program in BMI at ASU distinctive, if not unique, among such programs in the United States, in terms of diversity of experiences and opportunities available to students.

The required core curriculum features an introductory course, a two-semester sequence in methodology (Foundations of $\mathrm{BMI}$ ), and a course in problem solving with an emphasis on the latest software and systems solutions for BMI applications. The students' experience is rounded out with a series of elective courses in areas such as biostatistics, public health, cognitive decision-making, human-computer interaction and genomics. Students also work with the departmental faculty to select internship opportunities that might best support their particular area of interest in the field and to help them as they complete their graduate research. Building on the core courses, students are able to custom-tailor their programs, drawing on electives both inside and outside of the Department of BMI.

We require applicants to the M.S. program in BMI to have earned a bachelor's degree in computer science, biology, physiology, psychology, nursing, statistics, engineering, or a related field. We also consider student applicants who have earned degrees in other unrelated fields if they have also acquired appropriate academic grounding. How- 
ever, we require all applicants to have basic competencies in college-level calculus, general biology (or physiology), statistics, and basic computer programming. The applicant's undergraduate GPA and depth of preparation in their field are the primary factors in admission.

Ph.D. program. The Ph.D. program subsumes the requirements of the M.S. core curriculum while also including development of in-depth expertise in a selected area of concentration, thereby preparing graduates to assume advanced informatics research-and-development and leadership roles. The core program features five courses specifically designed to bring together clinicians, biological scientists, and informatics researchers in teams, applying new developments in informatics methods and theory to clinical or biological practice. While foundational coursework for $\mathrm{Ph}$.D. students does not differ significantly from that of M.S. students, the added concentration courses in an area of focus, and emphasis on independent research, are intended to place these students at the leading edge of the field. We expect applicants to the Ph.D. program to have similar backgrounds to applicants for the M.S. degree, but they must also show evidence of a strong commitment to and potential for research.

As with the M.S. program, our strong collaborative relationships with a variety of health care organizations, bioscience, industry, and governmental agencies provide an unparalleled opportunity for doctoral students to explore and contribute to advances in bioinformatics, or informatics related to imaging, clinical medicine, and public health, with special foci on cross-cutting areas such as cognitive science, data mining/predictive modeling, embedded sensors, and simulation. We have begun to accept applications for the $\mathrm{PhD}$ program for Fall 2008. Undergraduate program. An undergraduate program in BMI is in the plan- ning stages, to begin in 2009. There currently are very few undergraduate programs in North America, with the primary long-standing program located at the University of Victoria [7]. As noted above, the intent is not only to increase understanding and preparedness of undergraduates for employment in BMI but to attract them to our graduate programs. As such, we are focusing on development of a highly selective degree program, with an initial small number of students, primarily expected to draw on students entering the ASU Barrett Honors College, aimed at thorough academic preparation and practical experience to give students an understanding of the range of career opportunities and the foundations for taking on major responsibilities in those areas. With a number of other campus initiatives emphasizing the expanding role of technology and informatics in future workforce positions, stimulated in part by the National Science Foundation's Science, Technology, Engineering, and Mathematics (STEM) program (for example, see: http:// www.nsf.gov/funding/pgm_summ. jsp?pims_id=5257), we are seeking to integrate BMI into this effort. Other efforts at ASU, with which we are beginning to coordinate, are seeking to introduce these initiatives even at the high school level.

Medical student education. As briefly noted in Section 1, another unique aspect of the ASU BMI Department is the extent of its involvement in the medical school curriculum of the new Phoenix program. The curriculum is organized into nine body-system oriented blocks taught in Years 1 and 2, as well as a one week BMI block at the beginning of both Year 1 and Year 2 . All of the system-oriented blocks present core elements utilizing casebased instruction, virtual laboratories and interactive lecture techniques. Wo- ven through these blocks are experiences and content related to BMI. A Scholarly Project is required, which extends through all four years and for which BMI is one of the four areas of concentration. Finally, several key longitudinal courses are synchronized with block content and serve to amplify and integrate basic medical science and clinical connections. These include a Learning Community (in its first year comprising the entire class of 24 students), which is focused on key topics including those related to the Scholarly Projects), a Doctoring experience (to teach history taking, physical examination, presentation and clinical reasoning skills) and a Longitudinal Clinical Experience (LCE) in which students follow a panel of patients in a primary care setting during Years 1 and 2 .

Curriculum design was based on review of curricula from other academic centers, with a decision to base the curriculum on the AAMC Medical Students Objectives Project Report II, "Contemporary Issues in Medicine: Medical Informatics and Population Health", issued in June 1998 [8]. A modified final set of BMI learning objectives for the COM-PHX focused on four primary goals: (1) role as a life-long learner, (2) informatics competency, (3) electronic health record literacy, and (4) advancing the science of medicine. These learning objectives were used to design the curricular elements which follow:

System-oriented blocks: BMI instruction is integrated into the blocks in three ways: First, there are two one-week BMI sessions that occur at the beginning of each of Years 1 and 2. Second, the COM-PHX developed a systematized and sequenced process for creating the system-oriented blocks, which involved an explicit focus on identifying where BMI content can best be included in the interactive lecture schedule and in various labs (the same inte- 
gration effort was also done with Public Health, and Behavioral Sciences content). Third, all blocks utilize case- based instruction. Just as for the creation of blocks, the creation of these cases is includes explicit focus on identifying where BMI, Public Health, and Behavioral Sciences content can best be incorporated into the case under development.

Scholarly Project \& Learning Community: The Scholarly Project is intended to develop critical thinking, skills in evaluation of new data, an appreciation for the methods by which new scholarly information is generated, and skills for lifelong learning. This required component of the Phoenix curriculum provides medical students with faculty-mentored scholarly experiences and structured activities culminating in written 'and oral presentations in the middle of Year 4. Students select one of the following four areas of concentration areas for conduct of their Scholarly Project: (1) Biomedical Informatics; (2) Medical Humanities and Ethics; (3) Molecular Medicine; and (4) Public Health, Prevention, Population Health and Policy. Six of the first class of 24 students selected BMI as their concentration area.

Doctoring \& LCE: The Doctoring course in which students are instructed on history, physical examination and clinical reasoning is an ideal curricular location for BMI instruction, particularly with regard to electronic health record (EHR) literacy. A digital video recording system has been installed in each of the Clinical Education Suite examination rooms along with access to a sample ambulatory EHR system. This will be the instructional 'laboratory' for students in Years 1 and 2 with a shift of focus to inpatient EHRs during clerkship Years 3 and 4 . This is an ideal opportunity for students to learn how to access electronic decision support in response to specific issues arising in the care of their patient population.
COM-PHX initial BMI instruction was instituted in late summer, 2007, with the first class of entering medical students. Although typically academic calendars of engineering schools and medical schools are different, BMI faculty are all on 12-month contracts, so availability of faculty has not been an issue. For both COM-PHX and ASU-BMI access to real clinical and health care IT sites, we rely on an extensive set of collaborative relationships that have been established. For many years, approximately $40 \%$ of the medical students who matriculate at the UA College of Medicine - Tucson campus have taken all of their third and fourth-year clinical rotations in the Phoenix medical community and there are over 400 clinical faculty affiliate members located in Phoenix. These faculty members practice and teach within major medical centers located in Phoenix, and BMI has associations with all of these centers, as well as others that have already been developed through BMI research programs.

\section{Plans and Next Steps}

As can be seen from the foregoing, the ASU Department of Biomedical Informatics is in the early stages of an ambitious program of growth and development, in research, education, and community involvement. Its unique organizational framework and setting, coupled with an environment that is focused on partnering and rapid incorporation of computing and informatics methods and expertise to stimulate progress in biomedical research and health care delivery, with an emphasis on dissemination, community adoption, and demonstrable impact, are providing a strong impetus for the development of the Department's programs and initiatives.

Although the Department is less than a year old, it already is deeply involved in its educational mission, and has begun a number of partnering initiatives that are beginning to take shape. We hope to report on these developments in subsequent publications and on our website, http://bmi.asu.edu.

\section{Acknowledgment \\ The authors gratefully acknowledge the support of Da- vid Young, Senior Vice President for Academic Affairs, Arizona State University, not only for his review and suggestions on this manuscript, but more significantly for the major contributions he has made to the planning and realization of the Phoenix Biomedical Campus and the Department of Biomedical Informatics.}

\section{References}

1. Crow MM. A New American University: The New Gold Standard. Accessed at http://www.asu.edu/president/newamericanuniversity/, November 4, 2004.

2. Battelle Technology Partnership Practice. Report prepared for the Flinn Foundation, Overview of Technology Platform Strategies, (June, 2004); and Collaborative Economics, Report Prepared for the Arizona Department of Commerce, The Bioindustry in Arizona, June, 2001

3. Arizona Board of Regents. Memoranda of Understanding Regarding the Expansion of Medical Education and Research in Phoenix, August 4, 2004

4. Friedman CP, et al. Training the Next Generation of Informaticians: The Impact of "BISTI" and Bioinformatics - A Report from the American College of Medical Informatics. JAMIA 2004;11 (3):167-72.

5. Association of American Medical Colleges. Report II: Contemporary Issues in Medicine: Medical Informatics and Population Health, Medical School Objectives Project, June 1998.

6. National Institutes of Health. NLM Research Grants in Biomedical Informatics and Informatics (R01), PA number: PA-04-141, Release Date: August 13, 2004)

7. Kushniruk A, Lau F, Borycki E, Pratti D. The school of health information science at the University of Victoria: towards an intergrative model for health informatics education and research. Methods Inf Med 2006; 45 Suppl 1:159-65.

8. AAMC Medical Students Objectives Project, Contemporary Issues in Medicine: Medical Informatics and Population Health, http://www.aamc.org/ meded/msop/start.htm, June 1998.

\section{Correspondence to:}

Robert A. Greenes, M.D., Ph.D.

Department of Biomedical Informatics

Arizona State University

ABC-1, 425 N. 5th Street

Phoenix, AZ 85004

USA

E-Mail: greenes@asu.edu 